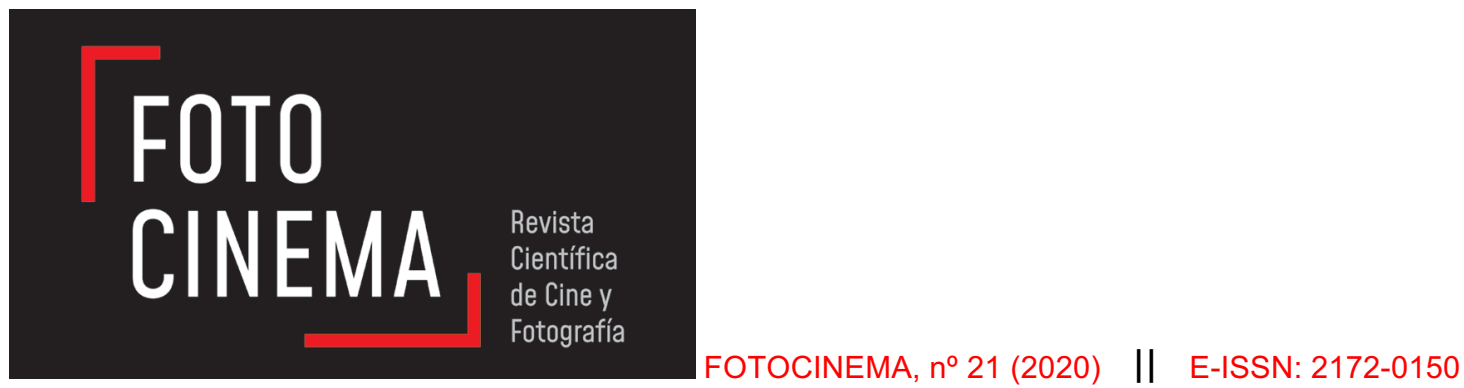

\title{
Eneas del siglo XXI: narrativas de la crisis migratoria en el cómic publicado en España (2014-2019)
}

\section{Aeneas of the 21st century: narratives of the migratory crisis in comics published in Spain (2014-2019)}

\author{
Raúl Álvarez Gómez \\ Universidad Rey Juan Carlos, España \\ raul.alvarez@urjc.es \\ https://orcid.org/0000-0002-2680-8660
}

\begin{abstract}
Resumen:
La crisis migratoria que afecta a Europa desde 2014 es un tema de interés para de los medios de comunicación de los países que reciben un mayor número de migrantes, principalmente España, Italia y Grecia. En el tratamiento de este fenómeno abundan las propuestas periodísticas y las películas, quizás porque estos son medios de amplia difusión. Son aproximaciones estudiadas en el marco de la representación audiovisual de fenómenos sociales. Este artículo se fija en un medio menos atendido, el cómic, en un país, España, que solo en 2019 recibió más de 23.000 migrantes. Se han localizado 13 títulos, publicados entre 2014 y 2019, que reflejan la migración a través de historias que enfatizan conceptos como huida, frontera y encierro. Este trabajo analiza esas obras desde un punto de vista semiótico para definir la iconografía, la expresión literaria y las técnicas narrativas que se proponen para representar la migración.
\end{abstract}

\begin{abstract}
:
The migrant crisis that has affected Europe since at least 2014 is a topic of interest for the media in countries that receive the largest number of migrants, mainly Spain, Italy and Greece. There is an abundance of journalistic reports and films about the phenomenon, perhaps because these are means of wide dissemination. Nonetheless, they can be considered approximations within the framework of audiovisual representations of social phenomena. This article focuses on a less-attended medium, the comic, in one particular country, Spain, which in 2019 received more than 23,000 migrants. A set of 13 titles has been located: published between 2014 and 2019, these reflect on migration through stories that emphasize concepts such as flight, border and confinement. This article analyzes these comics from a semiotic point of view to define the iconography, the literary expression and the narrative techniques that are employed to represent migration.
\end{abstract}

Palabras clave: cómic; inmigración; narrativa; estereotipos; color; dibujo.

Keywords: Comic; immigration; narrative; stereotypes; color; drawn. 


\section{Introducción y objetivos *}

En diciembre de 2010, la Revolución de los Jazmines contra el régimen de Ben Ali, en Túnez, provocó una oleada de movimientos similares en otros países del Norte de África y Medio Oriente que acabó conociéndose como la Primavera Árabe. El denominador común de estas revueltas populares fue un sentimiento general de indignación contra la represión, la miseria, el desempleo y la corrupción política que afectaba desde hacía décadas a naciones como Siria, Egipto, Marruecos, Libia, Mauritania, Yemen, Omán, Sudán y Líbano, y el territorio no autónomo del Sáhara Occidental (Moreno, 2011).

Como fenómeno, la Primavera Árabe produjo una serie de implicaciones políticas, económicas y sociales de impacto internacional, en particular, en Europa. Cabe destacar cuatro consecuencias: la aparición del Estado Islámico (ISIS), una nueva crisis del petróleo, el distanciamiento de Rusia de sus socios europeos y de Estados Unidos, y una crisis migratoria por la que millones de personas abandonaron estos países -principalmente Siria y Túnez- y pusieron rumbo al viejo continente y Estados Unidos (Zaccara \& Saldaña, 2015).

La retórica de los medios de comunicación de masas, con la televisión y la prensa digital en primer término, pronto generalizó y confundió los términos emigrante, inmigrante, migrante y refugiado (Zizek, 2016). A partir de las definiciones que ofrece el diccionario de la RAE, en este artículo se ha optado de manera habitual por migrante y, en ocasiones puntuales, por refugiado como sustantivos más adecuados. Así, migrante se define como la "persona que se traslada desde el lugar en que habita a otro diferente" (Diccionario de la lengua española, versión electrónica 23.3). Y refugiado es la "persona que, a consecuencia de guerras, revoluciones o persecuciones políticas, se ve obligada a buscar refugio fuera de su país" (Diccionario de la lengua española, versión electrónica 23.3).

\footnotetext{
* Este artículo es el resultado del Proyecto de Investigación I+D "La crisis del European Dream: hogar, identidad y éxodo en las artes audiovisuales". (HAR2017-85846-R) Programa Estatal de Investigación, Desarrollo e Innovación Orientada a los Retos de la Sociedad. Convocatoria 2017. Financiado por el Ministerio de Economía, Industria y Competitividad.
} 
Un informe de Naciones Unidas (ONU) cifra en casi tres millones el número de migrantes, la mayoría procedentes de países árabes, que pidieron asilo en Europa entre 2015 y 2016 (Trilling, 2018, p. 24). Según datos del Proyecto Missing Migrants 2019, estos fueron los años más duros de la crisis, cuando 8.926 personas murieron en la ruta del Mediterráneo, considerada la puerta de entrada más peligrosa a Europa ${ }^{1}$. Desde el inicio de la crisis migratoria, más de quince mil personas han fallecido en las cuatro vías de acceso de esta ruta: Libia-Italia (Mediterráneo Central), Marruecos-España (Mediterráneo Occidental) y Libia-Grecia y Siria-Turquía (Mediterráneo Oriental)².

Este artículo se fija en la representación que se ha hecho de esta tragedia en una selección de 13 cómics publicados en España principalmente entre 2014 y 2019, esto es, desde el inicio de la crisis hasta el último año que contemplan los estudios de las distintas organizaciones de Naciones Unidas y la Unión Europea que trabajan en este asunto. La imposibilidad de acceder a la producción gráfica en toda Europa justifica la elección de un solo país, máxime cuando este fue, después de Grecia e Italia, la nación que recibió un número mayor de migrantes irregulares en dicho periodo. Según la Guardia Europea de Fronteras y Costas (Frontex), más de 125.00o refugiados llegaron a las fronteras españolas entre 2014 y 2019 por la ruta del Mediterráneo y, en menor medida, por la de las islas Canarias, frente al más de un millón que lo hicieron por Grecia y los casi ochocientos mil que entraron por Italia3.

Para definir los límites de este trabajo se han tenido en cuenta solo los títulos que tratan de forma específica esta crisis migratoria y han sido publicados y/o traducidos al castellano en el mercado del cómic español, sin importar la nacionalidad de sus creadores. De este modo, la visión de los autores españoles se ha completado con la de otros nacidos en Francia, Argelia, Italia, Irán o Irak que han difundido su obra en España. La suma de estas sensibilidades conforma un corpus heterogéneo en forma y estilo, pero unido por un ánimo común: la voluntad de contar con imágenes y palabras -los

${ }^{1}$ El Proyecto Missing Migrants es una iniciativa de la Organización Internacional de las Migraciones (OIM).

2 Estadísticas de la OIM de los años 2015 y 2016.

3 Información publicada en: www.elespanol.com/mundo/europa/20200118/espanasegunda-entrada-inmigrantes-irregulares-union-europea/460454772_o.html 
cómics muestran a la vez que narran- una tragedia que aún no ha cesado. La lista de títulos se incluye en la bibliografía.

El análisis de estas publicaciones tiene un objetivo principal. Se trata de identificar las convenciones semióticas que emplean sus autores para retratar la crisis migratoria, y de establecer, en términos ideológicos, la finalidad discursiva de las mismas. En definitiva, si en estas obras se ofrece un punto de vista a favor o en contra de los migrantes y qué repertorio gráfico y literario se emplea para ello. Un segundo objetivo es determinar la cuota de mercado que han ocupado estas obras en la industria del cómic español, a fin de valorar su alcance entre la ciudadanía tanto en términos de difusión como de ventas. En síntesis, cuál ha sido la visibilidad y el alcance de esos títulos.

\section{Marco teórico y estado de la cuestión}

La propuesta se articula bajo la perspectiva de los estudios narrativos, y, en concreto, la consideración del lenguaje del cómic desde la semiótica. Esta decisión se justifica por esa doble condición del cómic como medio que muestra (dibujo) a la vez que narra (texto) en un orden secuencial. En esta definición coinciden Gubern - “un medio escripto-icónico basado en la narración mediante secuencias de imágenes fijas que integran en su seno textos literarios” (2001, p. 14)-, Eisner -“el cómic consiste en un montaje secuencial de palabra e imagen, y por tanto exige al lector el ejercicio superpuesto de sus facultades visuales y verbales" (2007, p. 10)- y McCloud -“ilustraciones yuxtapuestas a otras imágenes en secuencia deliberada, con el propósito de transmitir información y obtener una respuesta estética del lector" (2007, p. 17)-.

El análisis de esa estructura gráfica y literaria en los 13 cómics seleccionados se ha realizado agrupando distintas convenciones semióticas del lenguaje de la historieta en tres apartados: iconografía, expresión literaria y técnica narrativa, que se detallarán convenientemente en la metodología. Grosso modo, a la iconografía pertenecen elementos relativos a los encuadres, las perspectivas, los estereotipos y las situaciones arquetípicas. En la expresión 
literaria se aprecian los cartuchos o los globos con textos, las onomatopeyas y los letreros. Y en la técnica narrativa figuran recursos acerca del montaje de viñetas, el paso del tiempo, el punto de vista, la voz narrativa, el espacio, la secuenciación y la estructura de la narración.

Los primeros estudios semióticos del cómic aparecieron en la década de los años 70 en Europa, resumidos en Nöth (1990), D’Angelo y Cantoni (2006) y Mey (2006). La semiótica considera el lenguaje como un conjunto de códigos diversos. Esta noción, aplicada a la narrativa del cómic, significa que esos códigos, principalmente icónicos y literarios, pueden reducirse a unidades mínimas de representación. Koch (1971) y Hünig (1974) crearon taxonomías de estas unidades a partir de representaciones gráficas de personajes y lugares; también, de viñetas individuales y secuencias enteras. Y Gubern (1972) diferenció aspectos relacionados con la forma y el color.

Otros enfoques se han centrado en las secuencias de los cómics. Los trabajos más recientes que siguen esta línea pertenecen a Groensteen (1999), Dean (2000) y Miller (2001). Magnussen (2000) aplica en general la distinción de tipos semióticos de Peirce -iconos, índices y símbolos-, y Manning (1998) hace lo propio, aunque de forma específica, a las diferencias entre los estilos de representación realistas y abstractos. Los trabajos contemporáneos, tanto en Estados Unidos como en Europa, se han multiplicado desde la publicación de Entender el cómic (1993), del artista y teórico Scott McCloud. En él, McCloud introduce principios cognitivos para explicar la forma en que los lectores entienden tanto las imágenes individuales como las secuenciales. Por ejemplo, McCloud propone el principio de "cierre", por el cual la mente llena los espacios entre las viñetas para comprender una secuencia de imágenes.

Estas consideraciones semióticas se completan por una parte con datos cuantitativos del mercado del cómic español, y por otra con apuntes sobre la legislación migratoria de la Unión Europea y el trato que sus países dispensan a los migrantes. Ambos asuntos son de importancia en tanto los cómics analizados se dirigen a un público, pretenden reflejar una tragedia real y sus autores se posicionan sobre las decisiones que Europa ha tomado estos años sobre el tratamiento que debe darse a los migrantes. Estas 
cuestiones son tratadas en Historia de la UE. De los orígenes al Brexit (2019), de Donato Fernández Navarrete; La Unión Europea y la protección de los derechos fundamentales (2018), coordinado por Francisco de Asís Peña Díaz y Alejandro Sánchez Frías; el Anuario de la Inmigración 20152016 del Centro de Información y Documentación de Barcelona (CIDOB); Inmigración y emigración: mitos y realidades (2014), dirigido por Joaquín Arango, David Moya Malapiedra y Josep Oliver Alonso; y Crisis, inmigración y sociedad (2015), de María Elena Gadea y Francisco Torres.

Por último, se han tenido en cuenta trabajos específicos sobre el tratamiento de los migrantes en los medios. Destacan tres artículos recientes: Liberal expulsions, crisis, and graphic reportage in Spanish comics, de J.L. CataláCarrasco, en el monográfico Culture, crisis, and renewal in Spain (2017), publicado en la revista Romance Quarterly; Una misión irrenunciable. Refugiados y desplazados: representación en el audiovisual (2018), de María Marcos Ramos y Agustín Rubio Alcover, en el monográfico Refugiados y desplazados: representación en el audiovisual, en la revista Archivos de la Filmoteca; y Desplazamiento, emigración, exilio (2017), de Manuel Galeote, en el monográfico Exilio, migraciones, asilo y desplazamientos forzados, en la revista Transatlantic Studies Network.

\section{Metodología}

La investigación se llevó a cabo en dos fases. En la primera, se procedió a la búsqueda de cómics dedicados a la crisis migratoria publicados en España. Este examen permitió conocer también datos significativos sobre el mercado español de cómics, que se expondrán en el apartado 4 de este artículo. Y en la segunda, se analizaron dichas obras teniendo en cuenta dos criterios. Por una parte, las convenciones semióticas empleadas por cada autor, con el objetivo de concluir cómo se ha contado formalmente el fenómeno migratorio. Y por otra, el posicionamiento ideológico de cada autor con respecto a la crisis. 


\subsection{Fase de búsqueda}

La idea de analizar la representación de la crisis migratoria partió de un descubrimiento personal: el hallazgo en una librería de Alpha, de la guionista belga Bessora y el dibujante francés Stéphane Barroux. Narra la historia de Alpha, un africano de Costa de Marfil que quiere reunirse con su familia en París. Su viaje está salpicado de dificultades - mafias, corrupción, traficantes de personas- hasta que finalmente llega a la capital francesa y se topa con la incomprensión de las autoridades locales.

Conocía otros cómics sobre experiencias de migrantes, como Persépolis (Marjane Satrapi, 2000), The Arrival (Shaun Tan, 2006), Contrato con dios (Will Eisner, 1978), las historietas de The Yellow Kid4 (Richard F. Outcault, 1895-1898) y El manga de los cuatro inmigrantes (Henry Kiyama, 1931), pero no había pensado en ellos como hitos de un tema habitual en el cómic. La lectura de Alpha me animó a buscar otros títulos similares editados en España para saber si se estaba contando en viñetas la tragedia del Mediterráneo, y, en caso afirmativo, cómo se estaba haciendo.

Para realizar esa búsqueda investigué el mercado de cómics español con el objetivo de identificar aquellas editoriales que, por volumen de ventas o línea editorial, fueran susceptibles de estar publicando obras como Alpha. Una referencia sólida en este ámbito es Tebeosfera (www.tebeosfera.com), una revista digital especializada en el estudio de la historieta que ofrece también un catálogo de los cómics publicados en España. Vinculada a la Asociación Cultural Tebeosfera (ACyT), desde 2014, realiza un informe anual estadístico (Informe Tebeosfera) que determina cuatro puntos clave de la industria del cómic: sellos editoriales más activos, número total de novedades (traducidas y producidas en España), géneros más populares y procedencia de los títulos.

La localización de títulos se llevó a cabo mediante dos vías: una solicitud

4 Mickey Dougan, más conocido como The Yellow Kid, fue una de las creaciones más populares de Richard F. Outcault, que lo convirtió en el personaje principal de series como Hogan's Alley. Esta tira cómica apareció de forma simultánea en dos de los periódicos más vendidos de la época en EE.UU. el New York World de Joseph Pulitzer y el New York Journal de William Randolph Hearst. Hogan's Alley ocupa un lugar importante en la historia del cómic al tratarse de la primera serie en la que se emplearon "bocadillos" para escribir los diálogos de los personajes (Masotta, 1982: 21-22). 
formal por correo electrónico a las editoriales seleccionadas y una búsqueda personal en los catálogos on line de dichas editoriales, que permiten filtrar los resultados por autor, año, género, temática y palabras clave; se eligieron los términos "migración”, “emigración”, “crisis” y "refugiados”. Una tercera fuente fue el conocimiento del sector que he adquirido en mis años como investigador de cómics. Mi trato personal con algunos autores y editores me permitió conocer obras que quizá de otro modo no habría encontrado.

\subsection{Fase de análisis}

El análisis formal de cada título se realizó a partir de las convenciones semióticas más significativas del lenguaje del cómic. Ante la dificultad de clasificar unos códigos de representación en los que a menudo se solapa lo que se narra y lo que se muestra, se ha apostado por la articulación funcional de Gasca y Gubern (1988), quienes proponen tres apartados fácilmente identificables según la matriz semiótica de cada elemento contenido en ellos. Esto no evita, y así lo advierten los autores, solapamientos y tangencias, pero es un método útil para discriminar entre signos icónicos y signos literarios. A continuación se enumeran los signos elegidos en cada bloque, extraídos de la categorización de Gubern (1972) y Gasca y Gubern (1988).

En la iconografía se tienen en cuenta los encuadres, las perspectivas, los estereotipos, las situaciones arquetípicas y las metáforas visuales; se valora, en consecuencia, el estilo formal del dibujo. En la expresión literaria se aprecian los cartuchos y los globos con textos inscritos, la rotulación, las onomatopeyas y los letreros. Y en la técnica narrativa se estudia la estructura de la narración (intriga, acción principal y acción secundaria), la secuenciación de la acción (cronológica, in media res, in extrema res, alternante), la voz narrativa (primera persona, segunda persona, tercera persona), el punto de vista narrativo (omnisciente, interno, externo, alternante) y el espacio (físico, social y psicológico).

Este estudio formal se completa con una valoración ideológica del discurso de cada obra atendiendo al posicionamiento de sus autores. Se han fijado cuatro criterios de evaluación: razón que motiva la migración, experiencia del migrante, trato de las instituciones (Unión Europea y oenegés) y trato de la 
ciudadanía del país de acogida. Para ordenar y comentar los resultados de cada análisis se crearon cuatro fichas.

Ficha 1. Convenciones iconográficas

\begin{tabular}{|c|c|c|c|c|}
\hline $\begin{array}{c}\text { Encuadre } \\
\text { y perspectiva }\end{array}$ & Dibujo & Estereotipos & $\begin{array}{c}\text { Situaciones } \\
\text { arquetípicas }\end{array}$ & Metáforas visuales \\
\hline & & & & \\
\hline
\end{tabular}

Ficha 2. Expresión literaria

\begin{tabular}{|l|l|l|l|}
\hline Cartuchos y globos & Rotulación & Letreros & Onomatopeyas \\
\hline & & & \\
\hline
\end{tabular}

Ficha 3. Técnica narrativa

\begin{tabular}{|c|c|c|c|c|}
\hline Estructura & Secuenciación & Voz narrativa & Punto de vista & Espacio \\
\hline & & & & \\
\hline
\end{tabular}

Ficha 4. Posicionamiento ideológico del autor

\begin{tabular}{|c|c|c|c|}
\hline $\begin{array}{c}\text { Motivo de la } \\
\text { migración }\end{array}$ & $\begin{array}{c}\text { Experiencia del } \\
\text { migrante }\end{array}$ & Trato institucional & Trato social \\
\hline & & & \\
\hline
\end{tabular}

\section{Exposición de resultados y discusión}

Los resultados del estudio semiótico y del estudio ideológico se han organizado en cuatro apartados que permiten trazar una idea de cómo y bajo qué perspectiva política se ha contado el fenómeno de la migración en los cómics publicados en España. Es necesario hacer una precisión previa respecto a los autores, pues aunque la mayor parte de historietas son de artistas españoles, hay también títulos producidos en otros países que después se tradujeron y publicaron en España. Esta circunstancia amplía el alcance de la que podría haber sido solo una visión española de la migración.

Tabla 1. Nacionalidad de los autores

\begin{tabular}{|l|l|c|}
\hline \multicolumn{1}{|c|}{ Título } & \multicolumn{1}{c|}{ Autor/es } & Nacionalidad \\
\hline La grieta & C. Spottorno y G. Abril & España \\
\hline El vientre de la hiena & C. Baloup y C. Alliel & Francia \\
\hline Alpha & Bessora y S. Barroux & Bélgica-Francia \\
\hline
\end{tabular}




\begin{tabular}{|l|l|c|}
\hline Esclavos del trabajo & D. Bogdanska & Polonia \\
\hline Ilegal & E. Colfer, A. Donkin y G. Rigano & Irl.-Ing.-Ita. \\
\hline Asylum & J. de Isusi & España \\
\hline Las amapolas de Irak & B. Findakly y L. Trondheim & Irak-Francia \\
\hline Sansamba & I Franc y S. Martín & España \\
\hline Como si nunca hubieran sido & J. Gallego y J. Gallego & España \\
\hline Refugiada & J. Tessa y A. Gordillo & España \\
\hline Viñetas de vida & VV.AA. (10) & España \\
\hline Refugiados & VV.AA. (60) & España \\
\hline Un regalo para Kushbu & VV.AA. (11) & España \\
\hline
\end{tabular}

De los 13 títulos localizados, ocho son de autoría totalmente española y cinco de autores foráneos, todos ellos ciudadanos de países miembros de la Unión excepto Brigitte Findakly (Irak).

Otra consideración previa importante es el hecho de que ocho de los títulos estudiados fueron producidos -y algunos también premiados- por oenegés o instituciones españolas de política social. Ilegal contó con el apoyo de las organizaciones Migrant Voice, Women for Refugee y Greenwich Migrant Hub. Viñetas de vida fue producida con el apoyo de Oxfam Intermón en el marco de la campaña "Sí me importa". Como si nunca hubieran sido surgió de la colaboración de los autores con la organización porCausa, y parte de los derechos de las ventas se destinan a Médicos sin Fronteras.

Un regalo para Kushbu fue producida por la fundación Mescladís y la asociación Al-liquindoi, y coeditada por el Ayuntamiento de Barcelona. Asylum forma parte de la iniciativa "Memorias compartidas: una mirada al derecho de asilo desde las experiencias de asilo desde el franquismo", coordinado por la Comisión de Ayuda al Refugiado en Euskadi (CEAR) en colaboración con la Fundación Gernika Gogoratuz. Es una obra financiada por la Agencia Vasca de Cooperación para el Desarrollo y el Gobierno Vasco. Una parte de los derechos de las ventas de Sansamba se destinan a la oenegé Latitu Zero, en beneficio del pueblo senegalés de Sansamba. Refugiada cuenta con el apoyo de Proactiva Open Arms. Y Alpha. Abiyán ganó el premio Médicos sin Fronteras 2015. 


\subsection{Convenciones iconográficas}

Un informe del Alto Comisionado de Naciones Unidas para los Refugiados (ACNUR) publicado en 2018 indica que en la actualidad se producen más movimientos demográficos a causa de conflictos armados que en cualquier otro periodo desde el fin de la II Guerra Mundial. En concreto, se estima que hay unos 66 millones de personas desplazadas, ya sea dentro de sus países de nacimiento o fuera, en países extranjeros (Trilling, 2018, p. 66). La guerra es, por tanto, la causa principal de las olas de migrantes que llegan a Europa y otras regiones prósperas del planeta.

En ningún título analizado ese éxodo se produce por voluntad propia. Como Eneas del siglo XXI, los personajes de La grieta, Alpha, Asylum, Refugiada, Un regalo para Kushbu, Sansamba o Ilegal dejan atrás su hogar obligados por una circunstancia terrible: la guerra, y vinculada a ella el hambre, el paro, la persecución étnica y/o religiosa, la corrupción política y la falta de derechos civiles. El protagonista de Alpha huye de Costa de Marfil; en Un regalo para Kushbu, Bubakar escapa de Mauritania; en Ilegal, Ebo sale de un punto indeterminado del África subsahariana; en La grieta, sus protagonistas - personas reales- dejan atrás Siria, Marruecos y Afganistán, entre otros países; y en Las amapolas de Irak, Brigitte abandona Mosul.

Los dibujantes muestran estos hechos mediante dos estereotipos clásicos en el lenguaje del cómic -el villano y la víctima-, así como con situaciones arquetípicas relacionadas con la idea de peligro o amenaza. La expresión gráfica habitual de ambas convenciones aparece en ilustraciones de soldados crueles y sin escrúpulos, casas o edificios devastados por la acción de las bombas, barcas que se hunden en el mar, persecuciones por parte de policías y militares, matanzas y cadáveres abandonados. Alpha constituye un buen ejemplo de esta clase de representaciones iconográficas (F1).

La iconografía remite lógicamente al estilo de dibujo, el recurso expresivo que quizá diferencia con más claridad al cómic de otros medios populares. En las obras estudiadas se aprecian tres tendencias. La primera de ellas propone una figuración expresionista, es decir, los 
trazos remiten a figuras y objetos conocidos, pero sin vocación realista. La mencionada Alpha sigue esta línea, como también Refugiada, El vientre de la hiena, Como si nunca hubieran sido y los relatos de Un regalo para Kushbu. Es un estilo empático que busca sensibilizar al lector con la tragedia narrada a través de contornos gruesos, rostros esquemáticos y un uso emocional del color, en concreto, de las tonalidades frías. Esta estrategia tiene sentido puesto que la mayor parte de los relatos suceden de noche o en mar abierto, bajo el imperio de azules, negros y grises (F2).

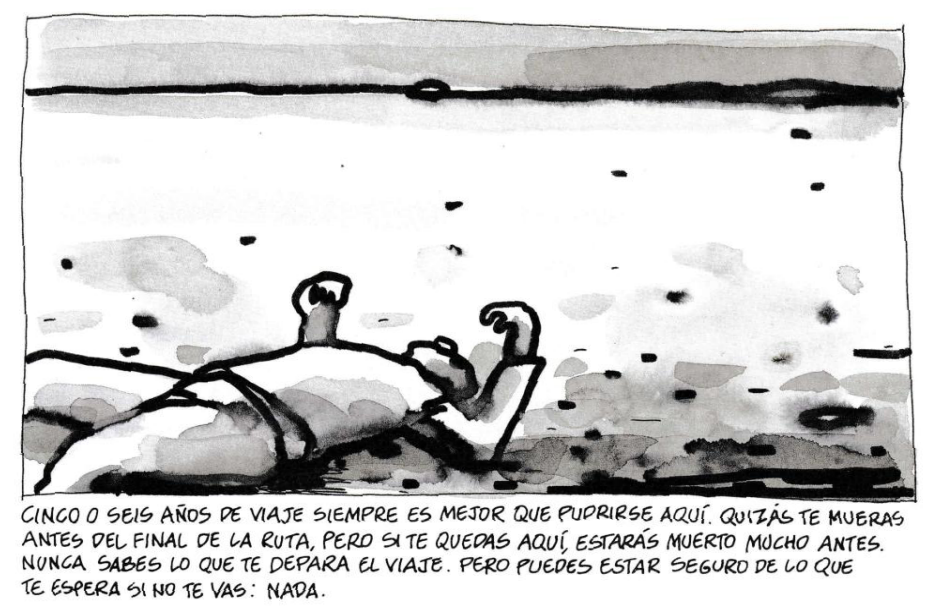

F1: Alpha (Bessora y Barroux, 2017).

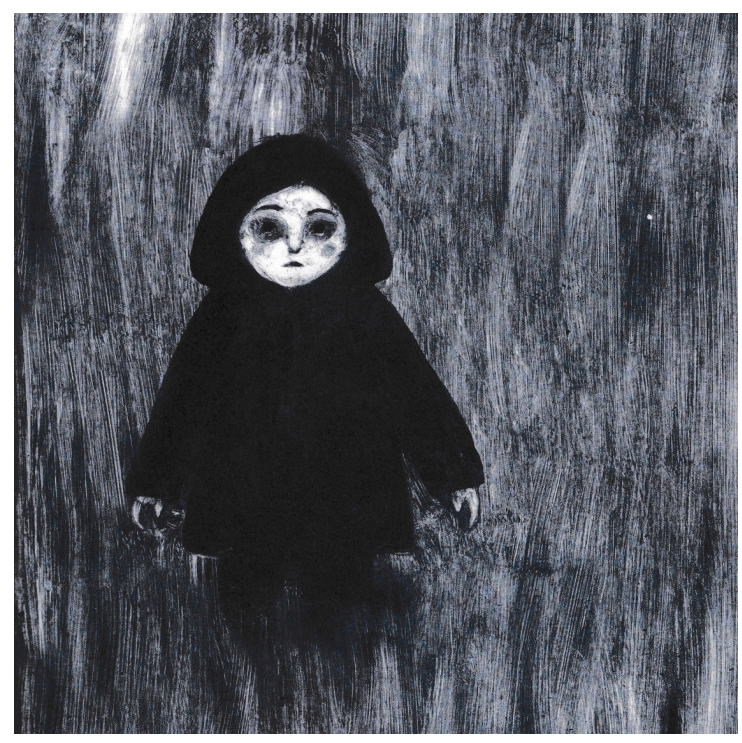

F2. Refugiada (Tessa Julià y Anna Gordillo, 2017). 
La segunda tendencia se acerca a los códigos representativos de la caricatura mediante el empleo de líneas claras y sencillas, gestualidad humorística, metáforas visuales que expresan el estado de ánimo de los personajes y símbolos cinéticos que enfatizan las acciones de estos. Las amapolas de Irak y Sansamba ofrecen numerosos ejemplos de este estilo que persigue el favor o la comprensión del lector a través de la ternura, la complicidad y la risa. El color es más suave y tenue, apenas unos toques para destacar algún elemento significativo en las viñetas.

La tercera tendencia apuesta por un estilo realista, como si de un trabajo periodístico o documental se tratara. Y es así en el caso de La grieta, cuya génesis es una serie de reportajes para el diario El País. Las viñetas son fotografías de Carlos Spottorno que han sido sometidas a un tratamiento cromático que acerca la estética de las imágenes a la de un dibujo. "No quería que pareciera una fotonovela y busqué cómo evitarlo convirtiendo las fotos en más ilustrativas y menos reales, potenciando los negros”, afirma Spottorno5. Ilegal y Asylum pueden adscribirse también a este corriente, si bien en una vertiente más cercana a la experiencia subjetiva que la que se le presupone a un proyecto periodístico como La grieta.

En general, la guerra y sus secuelas funcionan como motor iconográfico de las narraciones analizadas, lo cual supone ya un posicionamiento político por parte de sus autores. En una entrevista durante la promoción de Alpha en España, Bessora afirmó:

A título personal me indigna nuestra hipocresía respecto a los movimientos migratorios, pero ese no es el problema de Alpha: él es un pequeño vendedor de Abiyán que busca reunirse con su mujer y su hijo. Pero para él no basta con comprar un billete de avión. ${ }^{6}$

\subsection{Expresiones literarias}

La crisis migratoria de 2014 no fue un problema nuevo en la historia de los movimientos demográficos. En todo caso, fue y sigue siendo una situación

5 La cita corresponde a una entrevista concedida por Spottorno al diario El Periódico de Catalunya. Recuperado de https://www.elperiodico.com/es/ocio-ycultura/20170122/comic-la-grieta-refugiados-fronteras-ue-spottorno-abril-5741226

${ }_{6}^{6}$ Entrevista disponible en: $w w w . n o r m a e d i t o r i a l . c o m / b l o g / ? p=13534$ 
nueva para Europa, que pasó de recibir migrantes de países miembros de la Unión, los llamados “migrantes económicos" (Parutis, 2011, p. 37), a recibir migrantes desplazados de zonas deprimidas, es decir, refugiados. Con una problemática añadida: el tránsito hacia el viejo continente se efectúa por vías inseguras -el mar Mediterráneo y la frontera con Turquía- y medios precarios -a pie o en embarcaciones desprovistas de medidas de seguridad-.

El periplo hacia Europa es la parte sustancial de las experiencias migrantes relatadas en los cómics seleccionados, y en todos se representa como una tragedia para sus protagonistas. Puede hablarse a su vez de dos subtránsitos: uno, desde la localidad natal del migrante al lugar donde se encuentra el medio de transporte que lo conducirá a Europa; y otro, la marcha hacia Europa a través de zonas desoladas, como mares, montañas y desiertos, que funcionan como fronteras naturales entre el punto de partida y la meta.

Cada uno de estos subtránsitos se representa mediante códigos iconográficos que siguen las pautas explicadas en el punto 4.1., pero también, y es llamativo, se describen con palabras a través de convenciones literarias. Hay mucho texto que leer en los cómics analizados, y cada autor distribuye el contenido en una rica variedad de recursos que incluye bocadillos, globos, letreros, rótulos y onomatopeyas. En Ilegal, por ejemplo, es habitual la alternancia de estos códigos para combinar voces en primera y en tercera persona, o voz en off con voz en primera persona (F3).

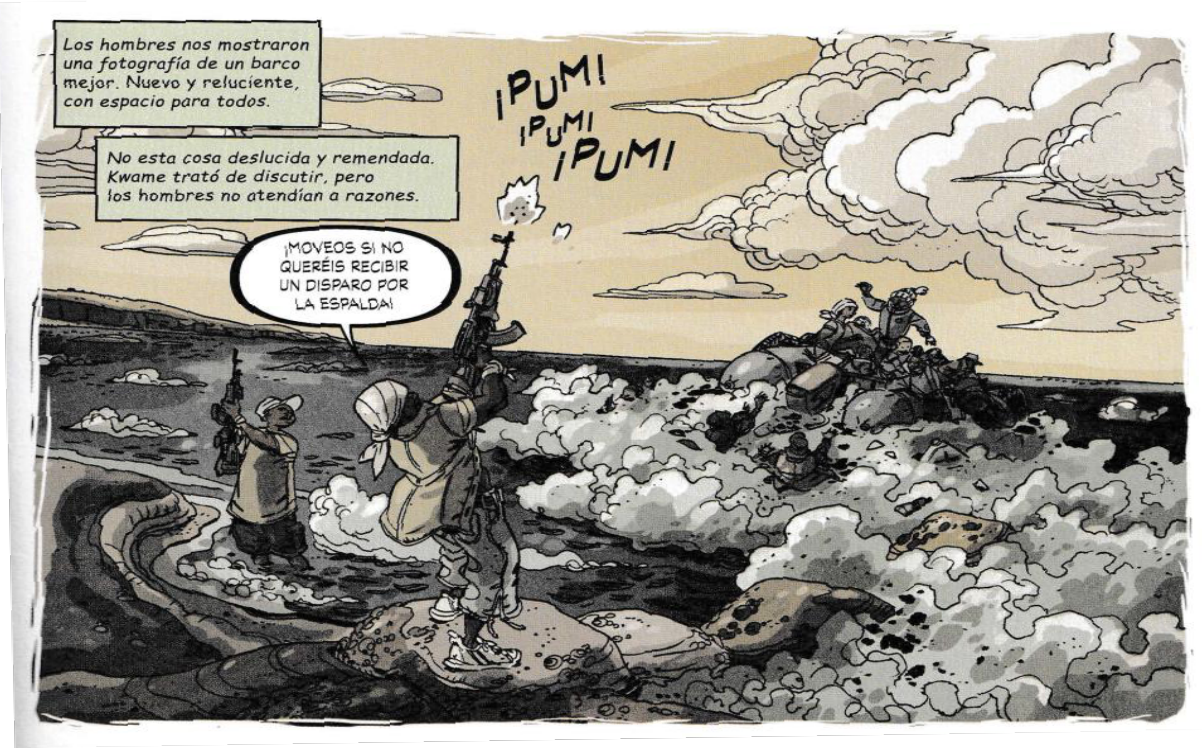


F3. Ilegal (Eoin Colfer, Andrew Donkin y Giovanni Rigano, 2017).

Aunque quizá la característica más interesante de los cómics analizados, desde el punto de vista de la expresión literaria, sea la constatación de que sus autores emplean tipografías de estilo script informal para expresar tanto la voz en primera persona de sus protagonistas como la voz en tercera persona del narrador. Los trazos curvos e irregulares de estas fuentes, que a menudo presentan ligaduras entre caracteres, sugieren que los relatos han sido escritos a mano y, por tanto, son reales. Adquieren, por emplear un símil narrativo de la novela, la cualidad de un diario personal. Se han identificado tres fuentes comerciales recurrentes: Brush Script, Mistral y Kaufmann Script.

La tipografía se convierte así en un elemento dramático de la historia, tanto más cuando a veces también se rotula con tonalidades que refuerzan el tono de lo narrado. Este puede ser trágico, tal es el caso de Como si nunca hubieran sido (F4), Alpha, El vientre la hiena y las historias breves incluidas en Refugiados. Viñetas solidarias, o amable, como en Las amapolas de Irak y Sansamba.

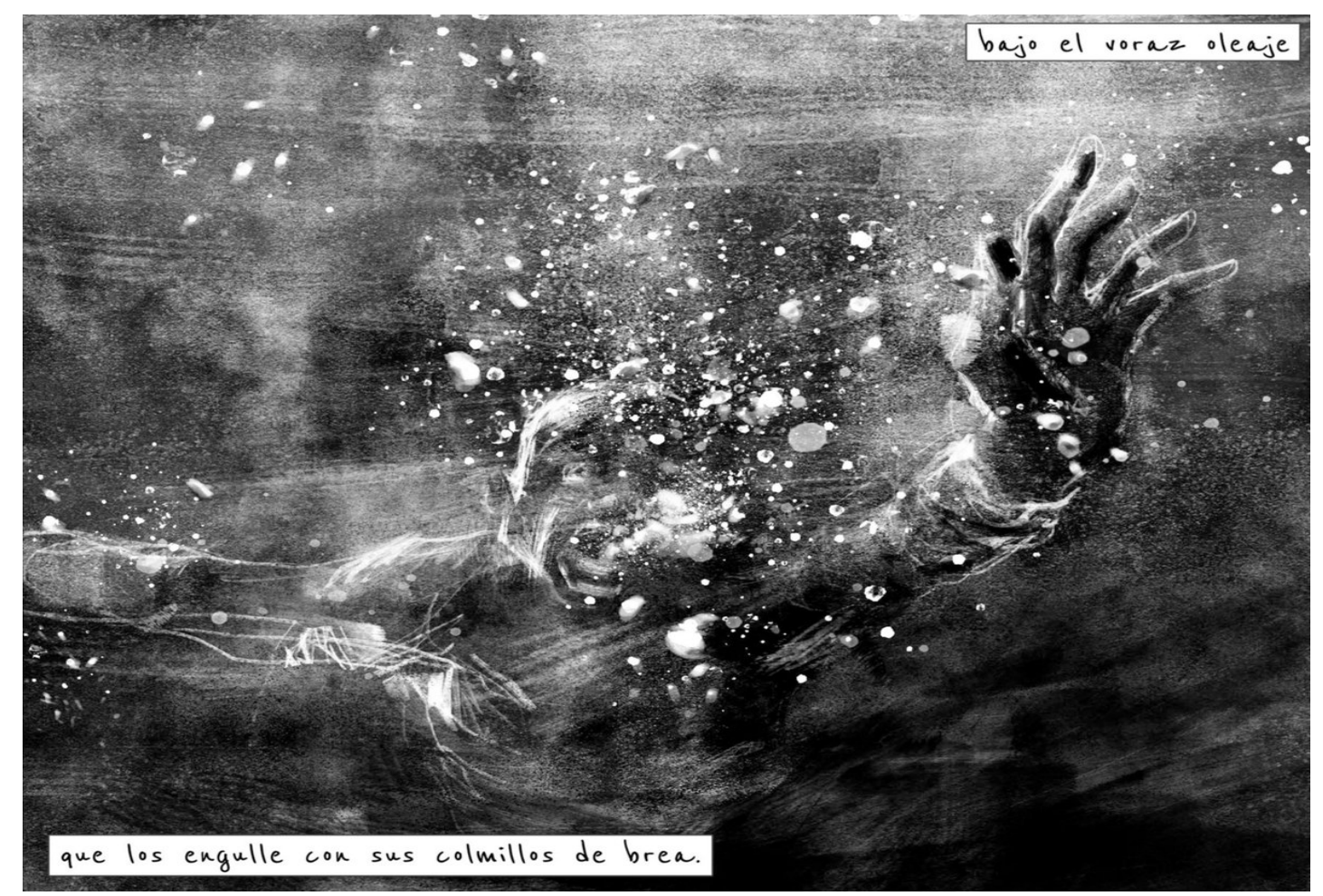

F4. Como si nunca hubieran sido (Juan Gallego y Javier Gallego, 2018). 


\subsection{Técnica narrativa}

La experiencia del migrante está estrechamente ligada a la idea del viaje, como se ha constatado en los puntos 4.1. y 4.2. Los refugiados que buscan cobijo en Europa emprenden una odisea que, en los cómics seleccionados, desemboca en uno de tres finales posibles: la muerte (Ilegal, Como si nunca hubieran sido), un estado de incertidumbre en centros de acogida (La grieta, Alpha) o la llegada feliz, tras meses o a veces años de dificultades, al país de acogida (Sansamba). Esta comprobación es significativa en términos de técnica narrativa porque los autores estudiados recurren al viaje como base estructural de sus relatos en el $\mathbf{9 2 \%}$ de los títulos. Solo la obra colectiva Refugiados. Viñetas solidarias se desmarca de esta tendencia apostando, en su lugar, por testimonios de personajes que hablan en primera persona de sus vivencias como migrantes en España.

La estructura del viaje inspira la trama principal, se enuncia siempre en orden cronológico y propicia un tipo de secuenciación que sigue un patrón prácticamente idéntico en ese $92 \%$ de los títulos. En él pueden diferenciarse cuatro etapas: conflicto, tránsito, frontera y meta. La etapa del conflicto se corresponde con el inicio de la historia, y presenta el motivo que empuja al protagonista o protagonistas a emprender el viaje a Europa. Lo habitual es que se trate de una guerra civil o una situación de pobreza extrema. Asylum, Esclavos del trabajo y la obra colectiva Un regalo para Kushbu plantean cuestiones menos habituales, como la persecución por motivos políticos o religiosos, y temas de identidad sexual.

La etapa del tránsito describe las primeras fases del viaje como acción física y de transformación vital del protagonista. Se ocupa fundamentalmente del choque entre éste y las fuerzas que parecen conspirar en contra de su sueño. Militares crueles, traficantes de personas y la Naturaleza se presentan como los peligros principales en los cómics de referencia. La etapa de la frontera incide en las barreras que levanta contra la migración la Unión Europea7. En

7 Amnistía Internacional cifra en 2 billones de dólares el presupuesto gastado entre 2007 y 
La grieta se repiten imágenes de vallas y verjas electrificadas, muros con alambre de espino, grupos de refugiados esperando una oportunidad para cruzar una frontera y fuerzas de seguridad armadas ( 55$)$.

La etapa de la meta, por último, relata el destino de los protagonistas, que no es siempre feliz. Más que llegada, de hecho, es un intento de llegada, pues la arribada a Europa suele dar pie al inicio de otro periplo, este de carácter burocrático, que suele abocar a los migrantes al rechazo y al posterior regreso a sus países de origen. Incluso quienes lo logran, como los protagonistas de Alpha, El vientre de la hiena y Sansamba, tienen por delante un tiempo de incertidumbre durante el cual se encuentran en un limbo legal. El migrante nunca abandona su condición de exiliado eterno. Por delante le espera un lento proceso de adaptación que incluye la concesión de papeles, la búsqueda de un trabajo y la aceptación en el seno de la sociedad como un individuo más. Esta situación se aprecia en títulos como Sansamba, Un regalo para Kushbu, Asylum y Alpha. 


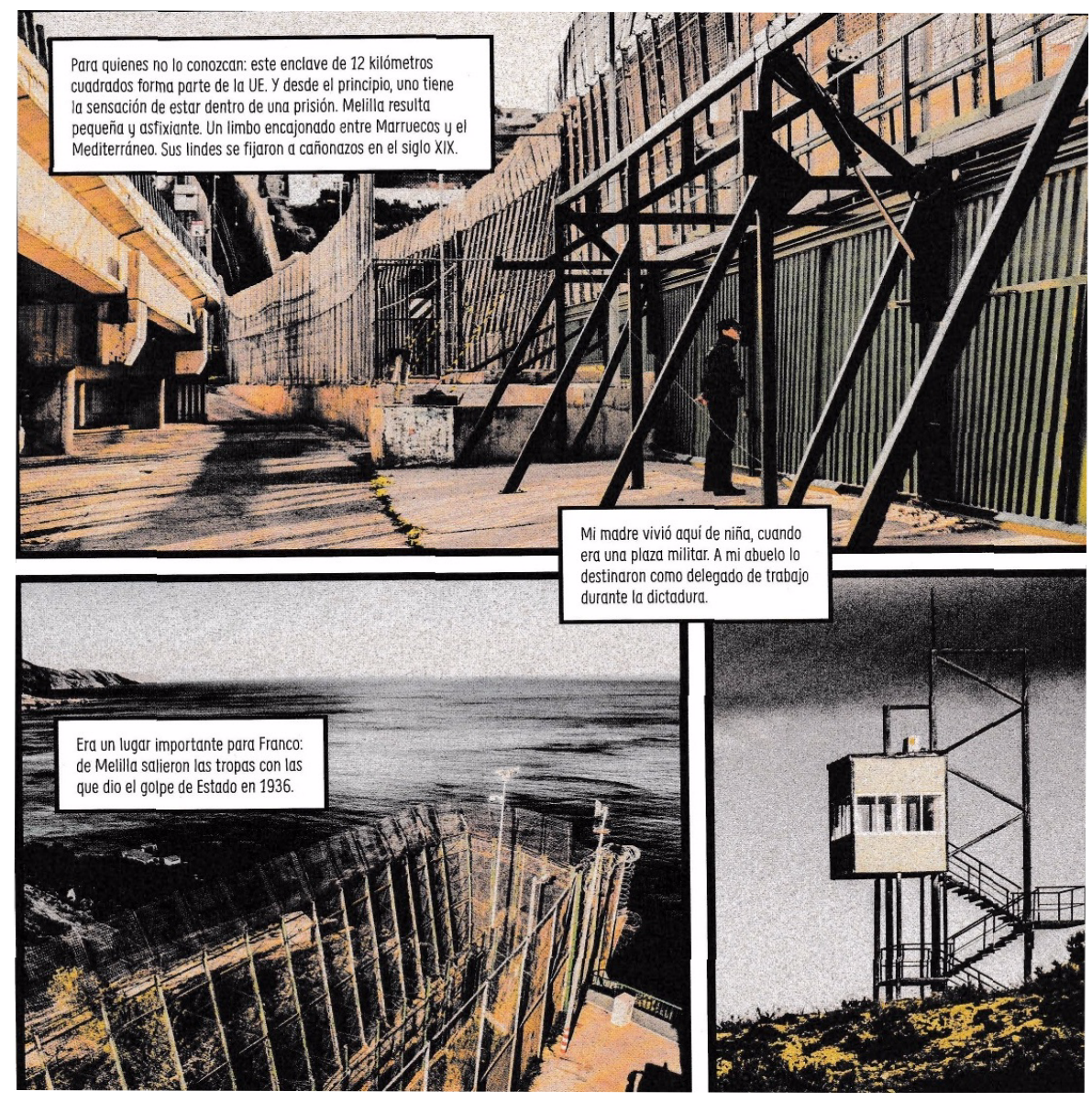

F5. La grieta (Guillermo Abril y Carlos Spottorno, 2016).

En estas cuatro etapas se observa además un empleo recurrente y alterno de las voces narrativas en primera y en tercera persona. Si la historia narrada responde a una experiencia real del autor -Brigitte Findakly cuenta en cómic su propia vida-, la voz se enuncia generalmente en primera persona, identificándose con un tipo de narrador protagonista u homodiegético. Si el relato es una invención del autor, la voz se enuncia en tercera persona, sugiriendo un tipo de narrador omnisciente. Hay casos singulares. En Como si nunca hubieran sido, por ejemplo, la voz narrativa en tercera persona funciona como un tipo de narrador testigo que no interviene en los acontecimientos, pero sí conoce el desarrollo de los mismos.

\subsection{Difusión y venta}

Para determinar la difusión y venta de los cómics seleccionados entre los lectores del mercado español, se recurrió al estudio que elabora cada año Tebeosfera. De la lectura de los informes correspondientes al periodo 2014- 
$2018^{8}$ se concluyó que las editoriales Panini, ECC, Norma y Planeta son responsables de dos tercios de la producción de cómics anual, unos 3.300 títulos de media. Los sellos que más apostaron por autores españoles y temas sociales -como la migración- fueron Astiberri, Norma, Dibbuks, Dolmen, Diábolo y Evolution, que publicaron cada año entre 7 y 17 cómics de creación nueva con estas características.

Estos datos coinciden con la selección de títulos propuesta en este artículo, puesto que seis fueron editados por Astiberri y tres por Norma. Del resto, uno es de Alianza, otro de La Galera, otro de Reservoir Books y otro de ECC. El mercado nacional se nutrió en buena medida de la traducción de historietas de otros países (70\%), y los cómics que se vendieron procedieron principalmente de tres ámbitos geográficos: el estadounidense, el japonés y el franco-belga. Casi el 60\% de los cómics publicados fueron de acción o de superhéroes, por solo un $12 \%$ de drama 9 .

Por desgracia, no hay datos contrastados sobre el número de ejemplares vendidos de estas obras, lo cual permitiría tener una idea de su difusión y posible impacto en los lectores; tampoco de otros títulos de cómics o novelas gráficas en castellano. Las editoriales no facilitan ese dato a la Federación de Gremios de Editores de España, solo la cifra total de sus ventas anuales, a menos que un título sea un gran éxito, ya que no son publicaciones sujetas a la Oficina de Justificación de la Difusión (OJD). Una buena recepción se cifra a partir de agotar la primera edición, un dato que en el mercado español del cómic referido al formato libro, es decir, el caso de esta investigación, se sitúa en torno a los mil o mil quinientos ejemplares ${ }^{10}$.

El único título que ha superado ese hito es La grieta, que en el momento de escribir estas líneas se encuentra agotando la segunda edición y ha sido traducido a cuatro idiomas, según la información que consta en la página web de Astiberri. Teniendo en cuenta que entre 2014 y 2018 se vendieron

\footnotetext{
8 El informe de 2019 no se había publicado en el momento de escribir estas líneas, pero sus datos no habrían cambiado sustancialmente la selección de editoriales.

9 Estos datos proceden de una baremación propia a partir de los informes de Tebeosfera.

10 Informe del sector editorial en España 2018.
} 
entre 250.000 y 300.000 cómics al año en España ${ }^{11}$, y que ninguno de los títulos estudiados, excepto La grieta, ha agotado la primera edición, se puede estimar en torno a 13.00o (mínimo) y 15.000 (máximo) el número de ejemplares vendidos de estas obras ${ }^{12}$.

\section{Conclusiones}

El presente artículo ha tratado de definir la visión de la crisis migratoria de 2014 que se ha ofrecido desde las páginas de los cómics dedicados de forma concreta a este tema y publicados en España. En esta muestra han cabido tanto autores españoles como autores de otros países cuyas obras han sido traducidas y distribuidas en el mercado español. Así, se han localizado 13 títulos. El análisis se ha planteado desde una aproximación semiótica al cómic como medio de comunicación, aunque se han tenido en cuenta también el contexto político del fenómeno migratorio, para determinar el punto de vista de cada autor, y la industria del cómic nacional, para cifrar el alcance y la difusión de las obras.

En respuesta al primer objetivo, que proponía una descripción de los códigos de representación empleados en el tratamiento de la crisis, cabe decir que todos los autores han estructurado sus relatos a partir de la idea del viaje, uno de los motivos clásicos en la narrativa occidental. Como Eneas del siglo XXI, los protagonistas de las obras analizadas parten de su tierra natal hacia Europa con la esperanza de crear un nuevo hogar, superando por el camino peligros de diversa naturaleza. El ámbito geográfico es incluso el mismo que el de la Eneida, el Mediterráneo, y la experiencia de los migrantes se narra en términos literarios parecidos a los que empleó Virgilio:

Se quiebran los remos, se vuelve la proa y ofrece el costado a las olas, viene después enorme un montón de agua; unos quedan suspendidos en lo alto de la ola; a estos otros se les abre el mar y les deja ver la tierra entre las olas en agitado remolino de arena. A tres las coge y las lanza el Noto contra escollos

\footnotetext{
${ }^{11}$ Informe del sector editorial en España 2018.

${ }^{12}$ Estos datos proceden de una baremación propia a partir de los informes de Tebeosfera y de la Federación de Gremios de Editores de España.
} 
ocultos (...), a tres el Euro las arrastra de alta mar a los bajíos y a las Sirtes, triste espectáculo, y las encalla en los vados y las cerca de un banco de arena (Virgilio, Libro I, 105-112).

Muchos de estos viajes de cómic, sin embargo, no tienen el final optimista del poema clásico, sino que ofrecen ilustraciones de muerte y desolación que tienen su referente real en las imágenes de naufragios y cuerpos ahogados ${ }^{13}$ que han difundido en los últimos años la televisión y la fotografía de prensa. En el viaje de los migrantes pueden diferenciarse cuatro etapas o secuencias: conflicto, tránsito, frontera y meta, cada una de las cuales se representa con una iconografía y una expresión literaria a veces común y otras divergente. Hay tres tendencias iconográficas. Una primera expresionista, que busca la sensibilidad del lector mediante un dibujo llamativo y la aplicación de colores contrastados. Una segunda caricaturesca, de tono amable, que sigue la línea del cartoon cómico. Y una tercera realista, de aspiración documental, que ofrece dibujos detallados o, como La grieta, fotografías tratadas.

Desde el punto de vista de la expresión literaria, se aprecia un predominio de las voces narrativas en primera y en tercera persona. Aunque solo un autor, la iraquí Brigitte Findakly, cuanta una experiencia real y propia, los demás apuestan por voces homodiegéticas que dan al lector la impresión de que el narrador es también el protagonista o un testigo de los acontecimientos que se cuentan. Se trata de una técnica que ofrece una sensación inmediata de realidad y, en consecuencia, de conocimiento íntimo del fenómeno.

Sobre el alcance y difusión comercial de los 13 cómics analizados, no existen datos oficiales que permitan cuantificar ni el número de ejemplares vendidos ni la cantidad de lectores que han podido acceder a estas obras. En España, la literatura no está sujeta a control por parte de la Oficina de Justificación de la Difusión, por lo que los únicos datos que se conocen son los que facilitan las editoriales, y estas suelen hacerlo únicamente con fines comerciales. Puede,

\footnotetext{
13 Uno de los motivos que convirtió la crisis migratoria de 2014 en un asunto de relevancia internacional fue la difusión en los medios de comunicación, el 2 de septiembre de 2015, de una fotografía que mostraba el cuerpo de Aylan Kurdi, un niño sirio de 3 años, ahogado en una playa turca (Marcos Ramos \& Rubio Alcover, 2018).
} 
eso sí, arrojarse una estimación en base a la tirada media que se lanza de los cómics en formato libro, que se sitúa entre 1.000 y 1.500 ejemplares, según datos cruzados del Informe Tebeosfera y la Federación de Gremios de Editores de España. Esta cifra oscilaría entre los 13.00o y los 15.000 ejemplares vendidos, pero es un cálculo totalmente discutible.

Por último, conviene señalar que todos los cómics investigados se posicionan claramente a favor de los migrantes. Son historias de tono humanista que tratan de abarcar la totalidad del fenómeno de la migración. Esto es, por qué y/o de qué huyen esas personas, cómo llegan hasta Europa, qué dificultades atraviesan, cuántos lo logran y cuántos no, qué trato se les dispensa desde las instituciones y qué grado de responsabilidad tiene el ciudadano que los ve como una otredad amenazadora. Los autores de estas propuestas intentan, en definitiva, ampliar la mirada ofreciendo un contexto.

Solo una de las obras analizadas, El vientre de la hiena, apunta los posibles efectos negativos de una mala política de integración de los migrantes. Sus protagonistas, dos hermanos del África subsahariana establecidos en la zona portuaria de Marsella, sobreviven como miembros de una banda criminal; creen que es más fácil delinquir que integrarse. Aun así, Talino, el más joven, lucha por abandonar la delincuencia y establecerse como un ciudadano de pleno derecho. Es la única desviación significativa en un conjunto de obras que coinciden en señalar las instituciones europeas y las burocracias locales -Sansamba es un buen ejemplo- como cómplices del fracaso en la gestión política y social de la migración. El hecho de que ocho de los 13 títulos hayan sido producidos gracias al apoyo de oenegés podría tener que ver con esta lectura ideológica de la situación. Da la sensación de que su concurso es vital para que estas obras salgan adelante en un mercado tan constreñido como el del cómic español, pero eso también puede suponer un lastre en cuanto a la riqueza de puntos de vista. Lo innegociable, sí, es la tragedia.

\section{Referencias bibliográficas}

Anuario CIBOD de la Inmigración. Nueva Época 2015-2016. Barcelona: CIBOD. 
Arango, J. (2007). Las migraciones internacionales en un mundo globalizado. Vanguardia Dossier, 22, p. 6-15.

Arango, J., Moya Malapiedra D. \& Alonso, J.O. (dir.) (2014). Inmigración y emigración: mitos y realidades. Barcelona: CIDOB.

Bryant, M. (2008). La II Guerra Mundial en cómic. Madrid: Libsa.

Carleton, S. (2014). Drawn to Change: Comics and Critical Consciousness. Labour / Le Travail (73), 151-177. Disponible en: https://www.jstor.org/stable/24244249?seq=1\#metadata_info_tab_c ontents

Catalá-Carrasco, J.L. (2017). Neoliberal expulsions, crisis, and graphic reportage in Spanish comics. Romance Quarterly, 4 (64), 172-184. DOI: https://doi.org/10.1080/o8831157.2017.1356139

McCloud, S. (2007). Entender el cómic. Bilbao: Astiberri.

Czaika, M. y De Haas, H. (2014). The Globalization of Migration: Has the World Become More Migratory? International Migration Review, 2 (48), 283-323. DOI: https://doi.org/10.1111/imre.12095

D'Angelo, M., \& Cantoni, L. (2006). Comics: Semiotics Approaches. En K. Brown (Ed.), Encyclopedia of Language and Linguistics Vol. 2: 627635. Oxford (GB): Elsevier.

Eisner, W. (2007). El cómic y el arte secuencial. Barcelona: Norma.

Estadísticas OIM (2017). Disponibles en: www.epdata.es/datos/inmigracionilegal-espana-grecia-italia-fallecidos-mediterraneo/156

Estudio de Amnistía Internacional (2017). Disponible en: www.care.org/emergencies/syria-crisis

Fernández Navarrete, D. (2019). Historia de la UE. De los orígenes al Brexit. Madrid: UAM Ediciones.

Gadea, M.E. \& Torres, F. (2015). Crisis, inmigración y sociedad. Madrid: Talasa.

Galeote, M. (2017). Desplazamiento, emigración, exilio. En "Exilio, migraciones, asilo y desplazamientos forzados". Transatlantic Studies Network, 2 (4), 31-38. Málaga: Universidad de Málaga.

Gasca, L. y Gubern, R. (2001). El discurso del cómic. Barcelona: Cátedra.

Groensteen, T. (1999). Systeme De La Bande Dessinée. París: Presses Universitaires de France.

Gubern, R. (1972). El Lenguaje de los cómics. Barcelona: Península.

Informe Tebeosfera (2018). Disponible en: www.tebeosfera.com/anexos/informe_tebeosfera_2018.pdf

Informe del Sector Editorial en España (2018). Disponible en: www.federacioneditores.org/datos-estadisticos.php 
Marcos Ramos, M. \& Rubio Alcover, A. (2018). Una misión irrenunciable. Refugiados y desplazados: representación en el audiovisual. En "Refugiados y desplazados: representación en el audiovisual". Archivos de la Filmoteca, 75, 13-18. Disponible en http://www.archivosdelafilmoteca.com/index.php/archivos/article/vi ew/652/606

Massimo, F. (2017). El asedio. Madrid: Editorial Popular.

Mey, K.-A. L. (2006). Comics: Pragmatics. In K. Brown (Ed.), Encyclopedia of Language and Linguistics Vol. 2: 623-627. Oxford (GB): Elsevier.

Nöth, W. (1990). Handbook of Semiotics. Indianappolis (EE.UU.): University of Indiana Press.

Parutis, V. (2014). "Economic Migrants" or "Middling Transnationals"? East European Migrants' Experiences of Work in the UK. International Migration, 1 (52), 36-55. DOI: https://doi.org/10.1111/j.1468-2435.2010.00677.x

Petersen, R.S. (2010). A History of Graphic Narratives. Westport (Connecticut, EE.UU.): Praeger.

Priego, A. (2011). La primavera árabe: ¿una cuarta ola de democratización? Revista UNISCI, 26, 75-94. Disponible en: https://www.redalyc.org/pdf/767/76718800004.pdf

Proyecto Missing Migrants (2018). Disponible en: www.epdata.es/datos/inmigrantes-muertos-desaparecidosmediterraneo-camino-europa/85

Salinas de Frías, A. y Martínez Pérez, Enrique J. (dir.) (2018). La Unión Europea y la protección de los Derechos Fundamentales. Valencia: Tirant lo Blanch.

Szmolka, I. (2013). El conflicto del Sáhara Occidental en el marco de la Primavera Árabe. Revista de Investigaciones Políticas y Sociológicas, 2 (12), 45-64. Disponible en: https://www.redalyc.org/pdf/380/38029545001.pdf

Trilling, D. (2018). Lights in the Distance. Londres: Picador.

Trilling, D. (2018). Five myths about the refugee crisis. Publicado en The Guardian el 5 de junio de 2018. Disponible en: www.theguardian.com/news/2018/jun/o5/five-myths-about-therefugee-crisis

Virgilio (2019). Eneida. Barcelona: Gredos.

Zaccara, L. y Saldaña, M. (2015). Cambio y estabilidad política en las monarquías del Golfo tras la Primavera Árabe. Revista CIDOB d'Afers Internacionals, 109, 177-199. Disponible en: https://www.jstor.org/stable/24364607?seq=1\#metadata_info_tab_c ontents

Zizek, S. (2016). La nueva lucha de clases. Los refugiados y el terror. Barcelona: Anagrama. 


\section{Cómics y novelas gráficas analizados}

Abril, G. \& Spottorno, C. (2016). La grieta. Bilbao: Astiberri.

Baloup, C. \& Alliel, C. (2016). El vientre de la hiena. Madrid: Norma.

Bessora \& Barroux, S. (2017). Alpha. Abiyán-Estación París Norte. Barcelona: Norma.

Bogdanska, D. (2018). Esclavos del trabajo. Bilbao: Astiberri.

Colfer, E., Donkin, A. \& Rigano, G. (2017). Ilegal. Madrid: Alianza.

De Isusi, J. (2017). Asylum. Bilbao: Astiberri.

Findakly, B. y Trondheim, L. (2016). Las amapolas de Irak. Bilbao: Astiberri.

Franc. I. y Martín, S. (2017). Sansamba. Barcelona: Norma.

Gallego, J. y Gallego, J. (2018). Como si nunca hubieran sido. Barcelona: Reservoir Books.

Tessa, J. y Gordillo, A. (2017). Refugiada. La odisea de una familia. Barcelona: La Galera.

VV.AA. (2014). Viñetas de vida. Bilbao: Astiberri.

VV.AA. (2018). Refugiados. Viñetas solidarias. Barcelona: ECC Cómics.

VV.AA. (2017). Un regalo para Kushbu. Historias que cruzan fronteras. Bilbao: Astiberri. 